\title{
Designing Activity-based Workspaces - An Analysis of Creativity Enhancers and Inhibitors in Physical Work Environments
}

\author{
Marc R ücker*, Oscar Pakos, Max Bauer and Kai-Ingo Voigt \\ School of Business, Economics and Society, Friedrich-Alexander University Erlangen-N ürnberg, \\ Lange Gasse 20, 90403 N ürnberg, Germany \\ * E-mail of the corresponding author: marc.ruecker@fau.de
}

\begin{abstract}
Employee creativity is the origin of every innovation and therefore crucial for a company's success. For this reason, the promotion of employee creativity is gaining more and more attention among practitioners and companies are increasingly implementing activity-based workspaces (ABWs) to improve the creative performance of their employees. Based on desk sharing and a mix of open and closed spaces, ABWs allow employees to select optimal working conditions for the task at hand. Nevertheless, literature is divided on whether ABWs effectively promote employee creativity and which ABW elements enhance or inhibit creativity. To close this research gap, we conducted interviews with ABW experts $(N=101)$. In the experts' accounts of creativity enhancers and inhibitors, the former were emphasized more strongly. Most of the identified enhancers and inhibitors were related more to the area of human resources and work practices (e.g., territorial flexibility, bustling activity) than physical layout and facilities (e.g., inspirational design, the person-environment fit) and organizational culture and structure (e.g., atmosphere, mindset), which indicates that employees and appropriate ABW use are the crucial factors for promoting creativity, while facilities serve mainly as enablers. These findings offer valuable guidance in designing and developing ABWs to foster employee creativity.
\end{abstract}

Keywords: activity-based workspace, physical work environment, creativity, innovation, qualitative study

DOI: $10.7176 /$ EJBM/14-4-01

Publication date: February $28^{\text {th }} 2022$

\section{Introduction}

As factories become increasingly automated, employee responsibilities are shifting from production work to knowledge work (DiGiovanni, 2004; Korczynski et al., 2002; Matsuyama, 2009). Given that knowledge workers spend most of their day in the office, this shift requires new types of the physical work environment (PWE) to support employees in their daily work (Budie et al., 2018). In recent years, companies have started implementing activity-based workspaces (ABWs), which provide support for different work situations by offering alternative types of space (e.g., open and closed) based on the desk sharing approach (Eismann et al., 2022) . Depending on their tasks and other needs, employees can choose the option that best suits their purposes (Appel - Meulenbroek et al., 2011; Veldhoen, 2005). Companies implement ABWs for a number of reasons: while costs and productivity are often the initial drivers, the range of reasons is likely to expand over time (Kim et al., 2016; Van Ree, 2002). In addition to enhancing employee satisfaction and well-being, there is evidence that ABWs can be used to strategically promote creativity (Suckley \& Nicholson, 2018), which can be defined as individuals' or groups' ability to generate new and useful ideas (Amabile, 1988). Especially during the COVID-19 pandemic, it has become clear that working from home makes ad hoc interactions and idea exchanges among employees less frequent and that the office environment offers better conditions for this purpose (Waizenegger et al., 2020). More specifically, ABWs' open design is considered to promote the flow of information and knowledge, which is crucial for idea generation (Boutellier et al., 2008). However, some studies have also reported that ABWs can inhibit creativity because open spaces may cause disruptions and reduce privacy (de Been \& Beijer, 2014; Halldorsson et al., 2021). In general, creativity is an important requirement for innovation, but little is known about which $\mathrm{ABW}$ elements specifically contribute to the enhancement or inhibition of creativity, and extensive qualitative studies are lacking. To bridge this knowledge gap, our study addressed the following research questions:

1. What reasons prompt companies to implement $A B W S$, and what role does creativity promotion play in this process?

2. Which $A B W$ elements enhance or inhibit creativity?

To answer these questions, we interviewed 101 experienced ABW experts from a range of companies and industries. The study findings contribute to a more holistic understanding of the relationship between ABWs and creativity.

\section{Theoretical Background}

2.1 Evolution and Characteristics of Activity-based Workspaces

As knowledge work has become increasingly important, companies have systematically modified the PWE to 
provide optimal employee support (Goodrich, 1986). However, conventional offices no longer meet knowledge work requirements: individual offices hinder communication between team members (de Been \& Beijer, 2014), and open-plan offices provide insufficient support for concentrated work (Kim \& de Dear, 2013). By providing different spaces for different activities within a single PWE, companies can enable employees to perform diverse tasks according to individual needs and preferences (Appel - Meulenbroek et al., 2011; Veldhoen, 2005).

Among modern PWEs, ABWs - also known as activity-based flexible offices, non-territorial work environments, or combi-offices (Wohlers \& Hertel, 2017; Kim et al., 2016; Suckley \& Nicholson, 2018)—were initially introduced primarily for reasons of space efficiency and costs (Appel - Meulenbroek et al., 2011; Van Ree, 2002). Companies realized that employees do not need their own permanent desks and that not all desks are in use all the time, as some employees are always out of the office-for instance, on business trips or on vacation Moreover, greater flexibility made it possible to save space and reduce furniture or equipment costs. As ABWs were considered modern and appealing, they were also used to attract new recruits in the war for talent (Bokor \& Fiset, 2019). Over time, it has become apparent that ABWs can also influence employee well-being and satisfaction (Appel-Meulenbroek et al., 2016) by increasing autonomy and encouraging constant movement in the workplace. In recent years, there has been an increasing focus on work practices as a means of influencing the workplace experience (Kingma, 2019; Waber et al., 2014). In particular, companies have implemented ABWs to enhance employee creativity through better exchange of ideas and knowledge, as workers constantly change places and discussion partners (Suckley \& Nicholson, 2018).

The framework for collaborative workplaces for innovation (Manca et al., 2018) can be used to classify the characteristic ABW elements. This framework is a particularly suitable basis for our study because ABWs are primarily designed to improve communication and collaboration, and the aim of this study is to explore ABWs' impact on creativity, the source of innovation. Figure 1 shows the four basic deployment areas of collaborative workplaces.

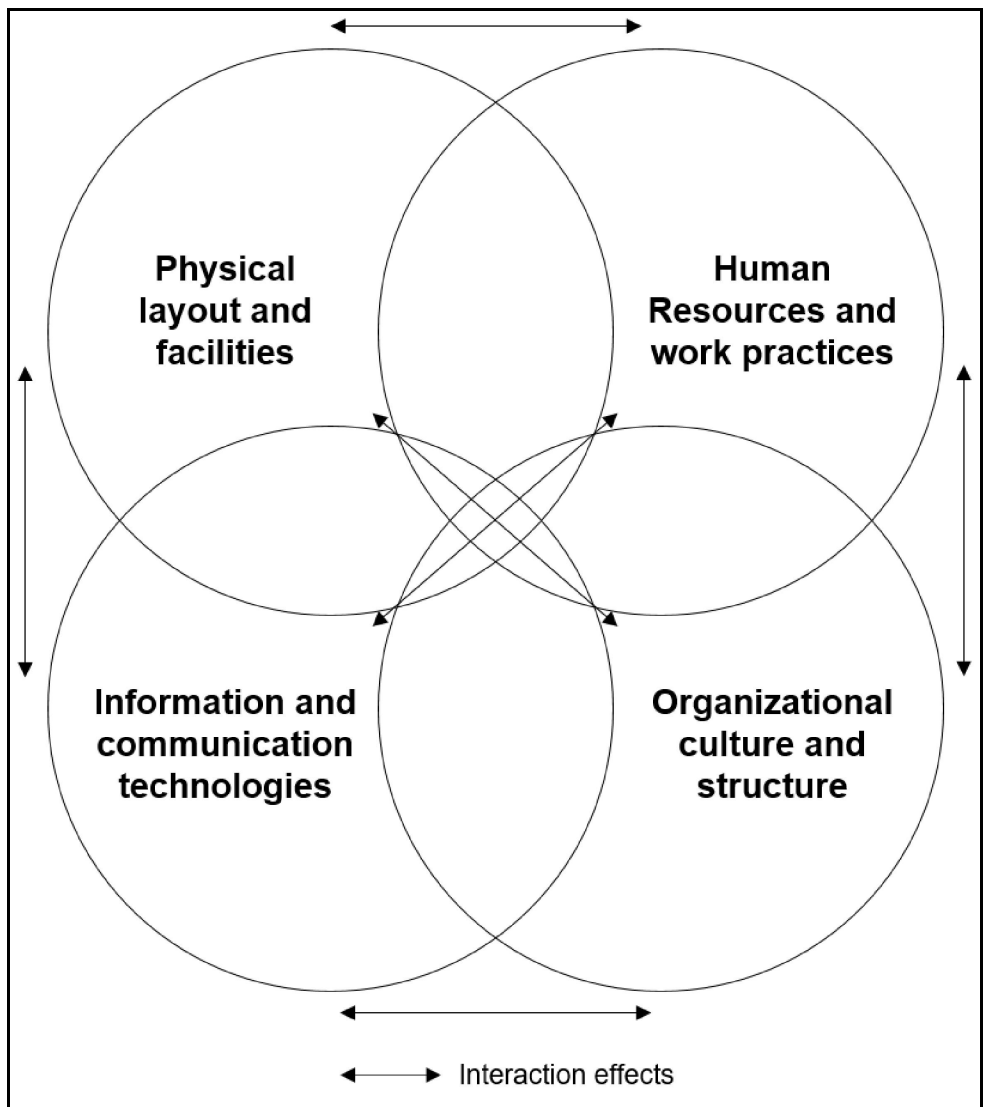

Figure 1. Collaborative workplaces for innovation: A conceptual framework (Manca et al., 2018).

In relation to physical layout and facilities, ABWs are tailored to employees' task needs to enhance work performance (Eismann et al., 2022; Haner, 2005) — for example, core workspaces are open or closed to support team or individual tasks, respectively. Open offices promote interactions among colleagues and spontaneous conversations but can also be used for individual work (Appel - Meulenbroek et al., 2011). Closed offices are designed to be noise free and are typically used for concentrated work on confidential tasks or phone calls (Maher \& Hippel, 2005). Finally, informal spaces, which are less common in conventional offices, include lounges, gaming rooms, sports facilities, and focus rooms. These spaces are intended to support creative work, 
social contacts, or thinking outside the box and to facilitate recreation and informal exchanges (Haynes et al., 2019; Thoring et al., 2018).

In $\mathrm{ABWs}$, desk sharing and knowledge sharing belong to the human resources and work practices deployment area. Desk sharing enhances territorial flexibility by allowing employees to select an optimal workspace for their next task. This practice also fosters communication and knowledge sharing - by sitting next to different people every day, employees come into contact with colleagues from other departments and teams (Hassanain et al., 2018; Kingma, 2019).

In terms of ABWs' organizational culture and structure, workers can determine when, where, and how they perform the tasks assigned to them. This is a feature of flat hierarchies, in which managers must trust their employees because the latter are dispersed across the workplace and cannot be controlled in the traditional sense. In turn, employees must take on more responsibility for delivering result-oriented work in light of their increased autonomy and must internalize the flexible spirit of the ABW-based corporate culture (Appel - Meulenbroek et al., 2011; Thanem et al., 2011).

Finally, the information and communication technologies deployment area provides the necessary technical support for facilitating activity-based working. To work in a flexible and location-independent way, employees need digital equipment, such as notebooks, smartphones, and headsets (Meli án-Gonz ález, 2019). ABWs promote the active use of communication technology for digital collaboration, and digital conferencing or meeting tools further support desk sharing and the use of different spaces (Kim et al., 2016). As envisaged by Manca et al. (2018), all four deployment areas are interrelated, and the individual elements must be appropriately combined to properly support activity-based working.

\subsection{Impacts of Activity-based Workspaces on Employee Creativity}

While the existing literature indicates that ABWs can support employees in their daily work, there is conflicting evidence regarding ABWs' actual impacts. Allowing employees to choose the most suitable space for their current task can help them work more productively (Appel - Meulenbroek et al., 2011; Haynes, 2008). At the same time, the new office setup and unfamiliar working practices mean that employees may need time to adapt, which, in turn, reduces their productivity (Arundell et al., 2018). In ABWs, closed spaces provide options for retreat and privacy, and this employee-centered approach can increase work satisfaction (Candido et al., 2019). However, working in open spaces may lead to interpersonal conflicts between colleagues who differ in their interpretations of workplace rules. For example, messy or disruptive colleagues may have a negative impact on others' work satisfaction (Kim \& de Dear, 2013).

There is also evidence of a link between PWE and employee creativity (Amabile \& Conti, 1999; Meinel et al., 2017; Suckley \& Nicholson, 2018). Creativity is present in all people and consists of motivation, knowledge, and creative-thinking skills (Amabile, 1983). Creativity is a trainable ability that constitutes the starting point of the innovation process in companies and can be influenced by the PWE (Amabile, 1988; Amabile \& Conti, 1999). In ABWs, all three types of space - open, closed, and informal — can influence employee creativity, and this relationship between space and creativity has been intensively discussed in the existing literature (Arundell et al., 2018; Hoff \& Öberg, 2015; Meinel et al., 2017; Wohlers \& Hertel, 2017). However, opinions remain divided as to whether ABWs' influence on creativity is positive or negative. For example, increased noise levels in open spaces can negatively impact creative capacity. Equally, co-workers may find it distracting if a colleague is searching for a new workspace or talking on the phone, which may lead to a loss of focus and hinder creative tasks (Hoff \& Öberg, 2015; Martens, 2011). Toker and Gray (2008) have argued that a lack of direct contact with colleagues in closed spaces inhibits exchange and innovativeness, as spontaneous ideas cannot be easily pitched to others and individuals are less likely to pursue these ideas in the absence of feedback. Desk sharing may also negatively impact employee creativity (Meinel et al., 2017). For example, being unable to furnish one's temporary desk with personal and individual items may reduce employee satisfaction and creativity (Samani et al., 2014). Finally, Engelen et al.'s (2019) comprehensive literature review on ABWs' effects on employees found no connection between creativity and activity-based working.

At the same time, scholars have also reported that ABWs have certain positive effects on creativity and improve the conditions for creative work. For example, open spaces promote interaction, which makes it easier to collaborate with other disciplines and generate novel ideas (Arundell et al., 2018; Coradi et al., 2015). The proximity of colleagues also facilitates picking up ideas and sharing knowledge (McCoy \& Evans, 2002), as people absorb knowledge in both planned and unplanned ways (Brunia et al., 2016; Wohlers \& Hertel, 2017). Even informal spaces can promote creativity through casual social interactions (Thoring et al., 2021). Conversing in a relaxed atmosphere tends to promote feelings of well-being and encourages the emergence of new ideas (Meinel et al., 2017). By contrast, closed spaces are more suitable for concentrated brainstorming, either alone or in a team. As concentrated work is known to encourage creativity (Blok et al., 2012; Martens, 2011; van der Voordt, 2004), quiet zones and closed spaces are often well suited to creative work and individual or team-based idea generation as well as quick and spontaneous gatherings with colleagues to work on new 
solutions. Therefore, desk sharing can be said to positively influence creativity by making such activities possible. By moving to other spaces and sitting next to different people, employees can change their perspectives and broaden their horizons, prompting them to think creatively or outside the box (Appel - Meulenbroek et al., 2011).

In summary, the literature indicates that $\mathrm{ABW}$ s can potentially enhance or inhibit creativity, primarily via physical layout and facilities.

\section{Methodology}

\subsection{Setting and Sample}

To address the research questions and deepen the current understanding of how ABWs enhance or inhibit creativity, we adopted a qualitative approach (Edmondson \& McManus, 2007) and conducted expert interviews to explore and identify patterns in a relatively neglected research area (Bettis et al., 2015; Yin, 2009). In addition, our large sample $(N=101)$ facilitated quantitative evaluations and the prioritization of employee statements (Mayring, 2004).

The sample included 70 men (69\%) and 31 women (31\%). On average, interviewees were 42 years of age and had 13 years of experience in their respective industries, and $47 \%$ worked in a management position. All interviewees had relevant experience in designing ABWs and had played a decisive role in implementing an ABW; overall, 91\% had worked or were currently working in an ABW. To ensure comparability, we verified before the study commenced that the workplaces in question matched the basic characteristics of ABWs, such as the provision of open, closed, and informal spaces for different tasks within a single work environment and support for autonomous employee access through desk sharing. As shown in Figure 2, most interviewees worked in small companies (1-200 employees). However, to ensure a balanced sample and to demonstrate that the findings are not confined to a specific company profile, we included German companies of all sizes.

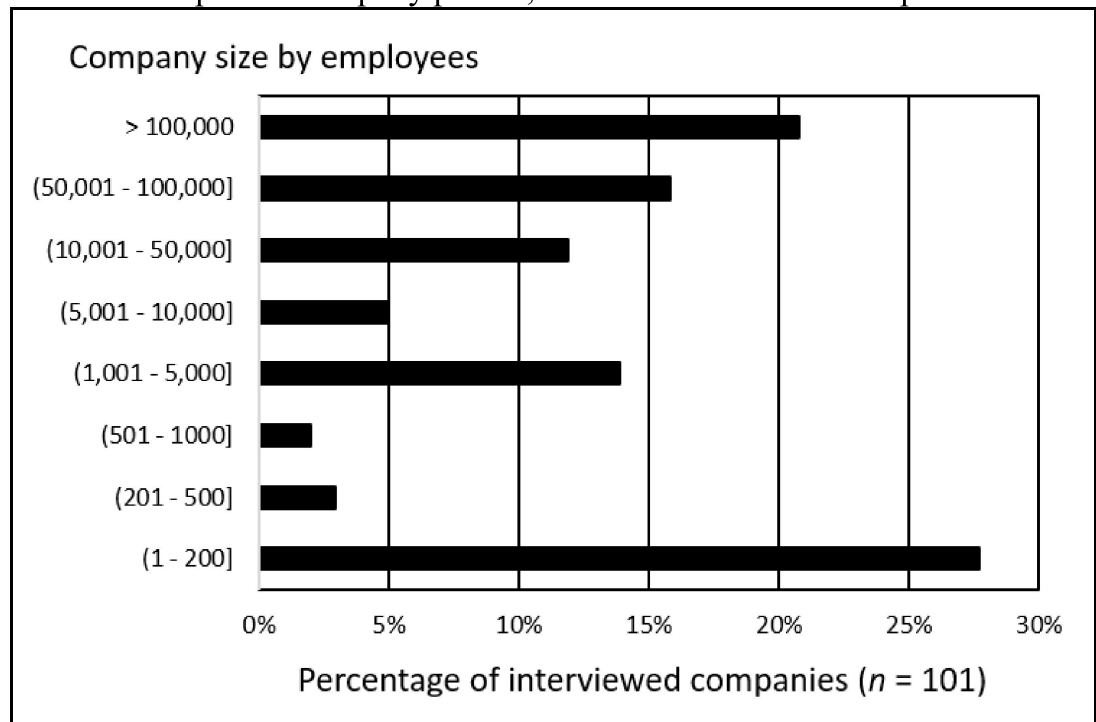

Figure 2. Classification of interviews by company size.

We specifically focused on recruiting a broad and diverse sample that included a range of different industries to provide a representative overview of $\mathrm{ABW}$ use across all sectors. As shown in Figure 3 , the experts were drawn from 18 industries, ranging from automotive $(14 \%)$ to telecommunications $(2 \%)$ industries. This heterogeneity means that the results can be generalized and any potential negative effects of sample bias can be mitigated (Yin, 2009). 


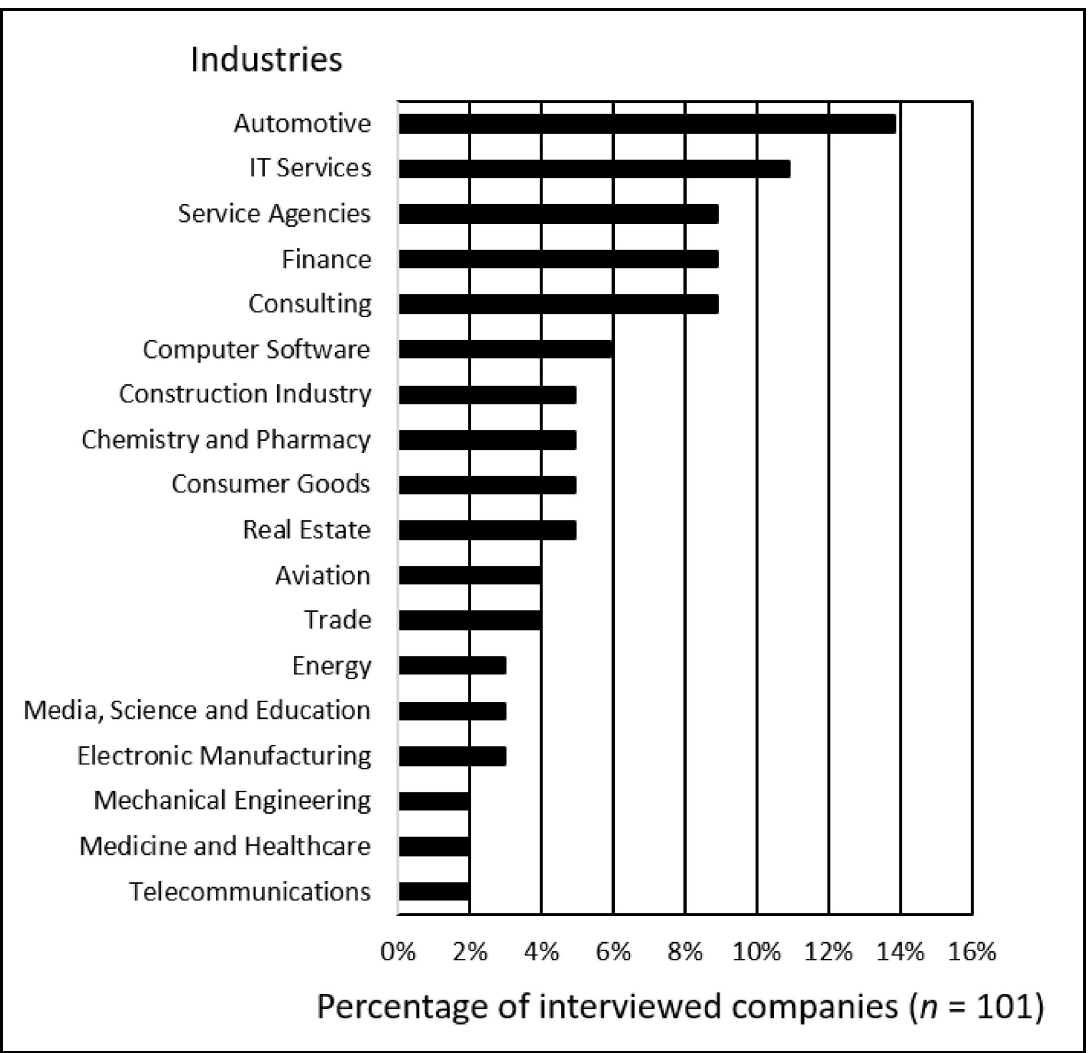

Figure 3. Classification of interviewees by industry.

\subsection{Data Collection and Analysis}

To begin with, potential interviewees were contacted by email or through business-related social networks. Interviews were conducted by telephone or web conferencing between June and December 2020 and were audiorecorded. Participation was voluntary, and interviewees were assured in advance that their names and companies would be anonymized to avoid any constraints on their answers (Yin, 2009). Participants were also informed in advance that the interview would focus on ABWs' effects on employees. To avoid any undue influence or sensitization, no reference was made to the topic of creativity. The interviews were semi-structured and based on an interview guideline from which the interviewer could choose to depart, depending on how the conversation developed (see Appendix A1). In this way, it was possible to combine structured and open data collection (Cannell \& Kahn, 1968). To make the very complex topic of creativity easy for the interviewees to understand, a brief definition of creativity according to Amabile (1988) was presented during the interview.

To facilitate the interview analysis, the audio recordings were transcribed and anonymized. In the first analysis step, the research team coded the interviews and used qualitative content analysis to identify categories that could help answer the research questions (Mayring, 2004). As shown in Table 1, the experts' statements were paraphrased and generalized to achieve a higher level of abstraction.

Table 1. Example of Qualitative Content Analysis

\begin{tabular}{|c|c|c|c|c|c|}
\hline $\begin{array}{l}\text { Question } \\
\text { Which } \\
\text { aspects of } \\
\text { ABWs make } \\
\text { employees } \\
\text { more } \\
\text { creative? }\end{array}$ & $\begin{array}{l}\text { Interview / Line } \\
\text { I1 / } \\
\text { L. 172-174 }\end{array}$ & $\begin{array}{l}\text { Quote } \\
\text { "The fact that you } \\
\text { can change } \\
\text { workplaces from } \\
\text { time to time, that you } \\
\text { get to hear more, and } \\
\text { that you're in contact } \\
\text { with different people, } \\
\text { I believe these } \\
\text { features make people } \\
\text { more creative." }\end{array}$ & $\begin{array}{l}\text { Paraphrase } \\
\text { ABWs make } \\
\text { employees more } \\
\text { creative by } \\
\text { allowing them to } \\
\text { move between } \\
\text { workspaces and } \\
\text { talk with new } \\
\text { colleagues. }\end{array}$ & $\begin{array}{l}\text { Generalization } \\
\text { Moving between } \\
\text { workspaces. } \\
\text { Discussions } \\
\text { with new } \\
\text { colleagues. }\end{array}$ & $\begin{array}{l}\text { Category } \\
\text { Top code: } \\
\text { Territorial } \\
\text { flexibility } \\
\text { Sub code: } \\
\text { Availability of } \\
\text { different } \\
\text { workplaces } \\
\text { Top code: } \\
\text { Increased } \\
\text { communication } \\
\text { Sub code: } \\
\text { Changing } \\
\text { discussion } \\
\text { partners }\end{array}$ \\
\hline
\end{tabular}


In the second step, the generalized statements were grouped into appropriate categories and the frequency of statements within categories was quantified to weigh and prioritize categories (Nardo, 2003). Such inductive development of categories was recommended by Gioia et al. (2013) as a means of deriving new insights and maintaining an exploratory approach. In each category, top codes and the related sub codes were created for each of the following three main study topics: (1) companies' reasons for implementing ABWs, (2) ABW elements that enhance creativity, and (3) ABW elements that inhibit creativity. In the final analysis step, a researcher reviewed the quotations, codes, and sub codes for comprehensibility and made sure that the interviewees' opinions were not distorted. The number of top codes and sub codes was unspecified at the outset and emerged during the analysis.

\section{Findings}

The 101 interviews generated a significant amount of data. Figures 4-6 summarize the top codes and the number of mentions in relation to the three main research topics. As no limits were imposed on interviewees regarding the length and number of answers, multiple mentions could be assigned to a given top code. Detailed information about the top codes and the corresponding sub codes, along with example statements, can be found in Appendices A2-A4.

The interviewees cited several reasons for implementing ABWs $\left(n_{\mathrm{r}}=303\right)$. As shown in Figure 4 , these answers were grouped into 14 top codes $\left(n_{\mathrm{r} 1-14}\right)$ comprising 50 associated sub codes.

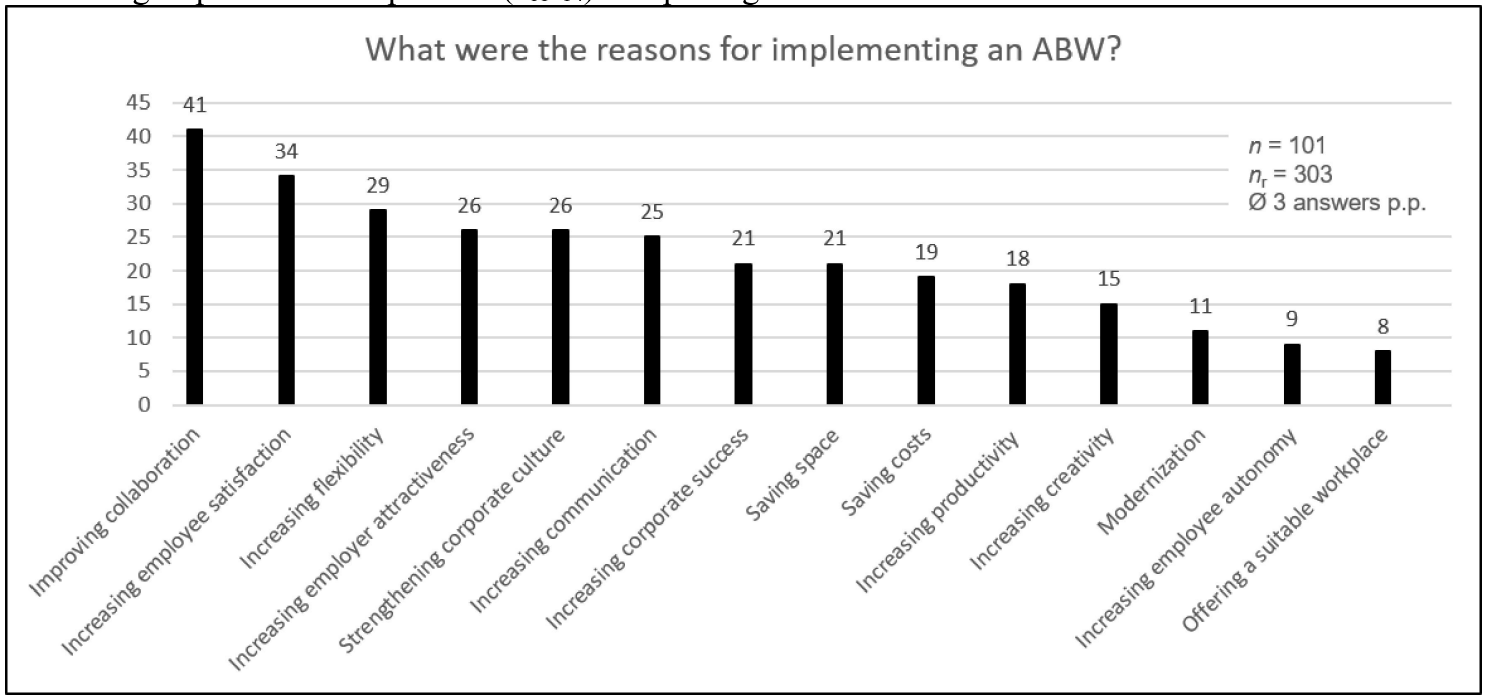

Figure 4. Reasons for implementing ABWs.

The highest relevance was assigned to the top code Improving collaboration $\left(n_{\mathrm{r} 1}=41 ; 13.5 \%\right.$ of all answers) - for example, this top code includes the sub codes Fostering interdisciplinary exchange and Enabling spontaneous meetings. The following example statement clarifies the meaning of this top code:

"The advantage of working in an ABW is that, in the best case, you are much more collaborative [...] because people don't just sit in their own rooms, they get to know much more about each other." (Expert \#15)

The second most mentioned top code Increasing employee satisfaction $\left(n_{\mathrm{r} 2}=34 ; 11.2 \%\right)$ includes sub codes such as Increasing employee well-being and Improving work-life balance.

"If employees are satisfied and happy with their jobs, they will also enhance company performance. I think that always has to be the goal-a focus on people." (Expert \#17)

The third most mentioned top code was Increasing flexibility $\left(n_{\mathrm{r} 3}=29 ; 9.6 \%\right)$, which includes sub codes like Increasing agility and Easier building of project teams.

"The original motivation [...] was to promote reaction speed and agility." (Expert \#79)

The top codes Modernization $\left(n_{\mathrm{r} 12}=11 ; 3.6 \%\right)$, Increasing employee autonomy $\left(n_{\mathrm{r} 13}=9 ; 3.0 \%\right)$, and Offering a suitable workplace $\left(n_{\mathrm{r} 14}=8 ; 2.6 \%\right)$ were mentioned the least frequently.

Responses to the question of which ABW elements can inhibit creativity $\left(n_{\mathrm{ci}}=121\right)$ were grouped into nine top codes $\left(n_{\text {cil-9 }}\right)$ comprising 34 sub codes. Figure 5 shows the ranked responses. 


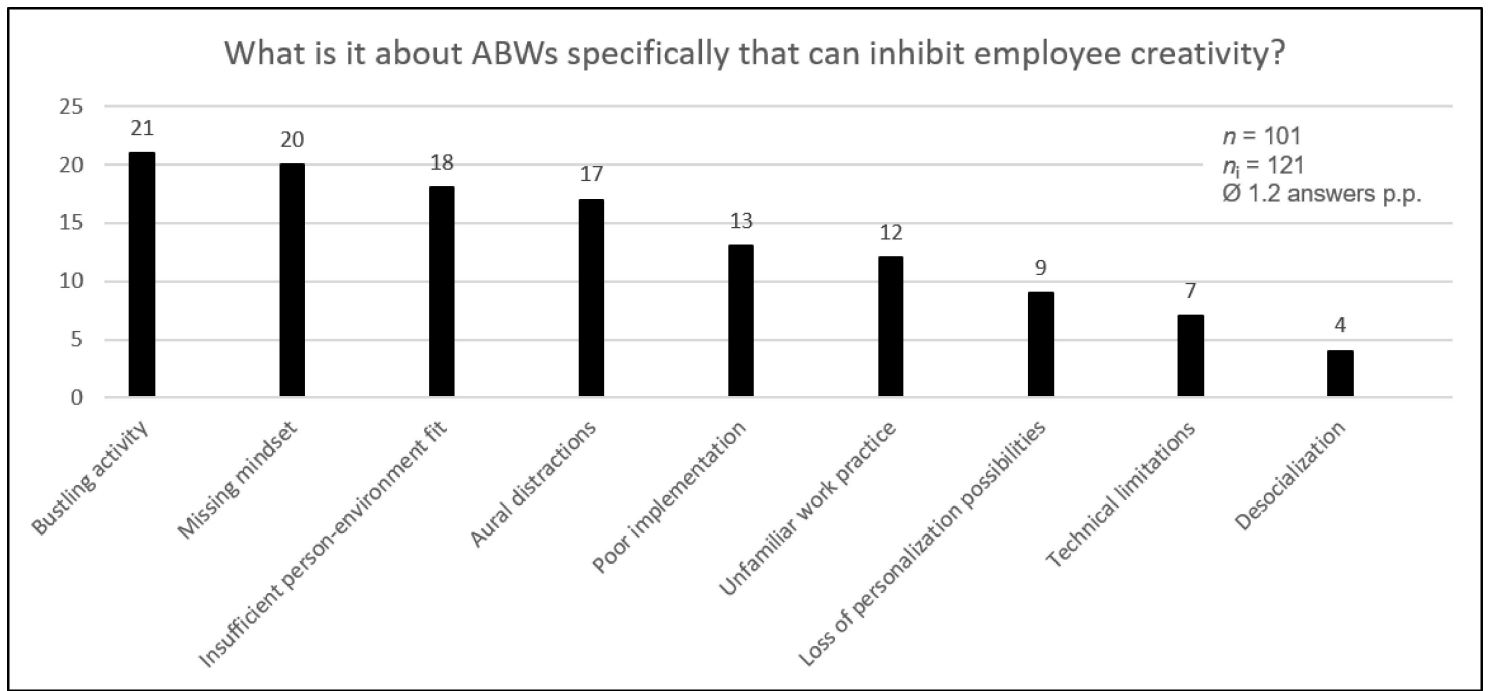

Figure 5. ABW elements that inhibit creativity

The results show that Bustling activity $\left(n_{\mathrm{ci} 1}=21 ; 17.4 \%\right)$ was blamed the most often for inhibiting employee creativity in ABWs; the sub codes include Disruptive behavior of others and Concentration difficulties. The following example statement clarifies the meaning of this top code:

"I feel I can't concentrate at all because there are too many people around me, so then I can't be creative either." (Expert \#10)

In second place, Missing mindset $\left(n_{\mathrm{ci} 2}=20 ; 16.5 \%\right)$ included Not following the rules and Not accepting the concept.

"If an employee does not accept this modern way of working, [they might say] 'I can't work like this, I'm not creative here. '” (Expert \#29)

This was closely followed by the top code Insufficient person-environment fit $\left(n_{\mathrm{c} i 3}=18 ; 14.9 \%\right)$, which includes the sub codes Wrong/poor ABW design and Lack of free suitable workplaces.

"I think if you get the design of the work environment badly wrong [...] people are not creative at all." (Expert \#34)

The least mentioned creativity-inhibiting elements were Loss of personalization possibilities $\left(n_{\mathrm{c} i}=9 ; 7.4 \%\right)$, Technical limitations $\left(n_{\mathrm{ci} 8}=7 ; 5.8 \%\right)$, and Desocialization $\left(n_{\mathrm{ci} 9}=4 ; 3.3 \%\right)$.

During the study, the experts also mentioned ABW elements that can enhance creativity $\left(n_{\mathrm{ce}}=196\right)$. Figure 6 shows the 14 top codes $\left(n_{\mathrm{ce} 1-14}\right)$ comprising 48 sub codes.

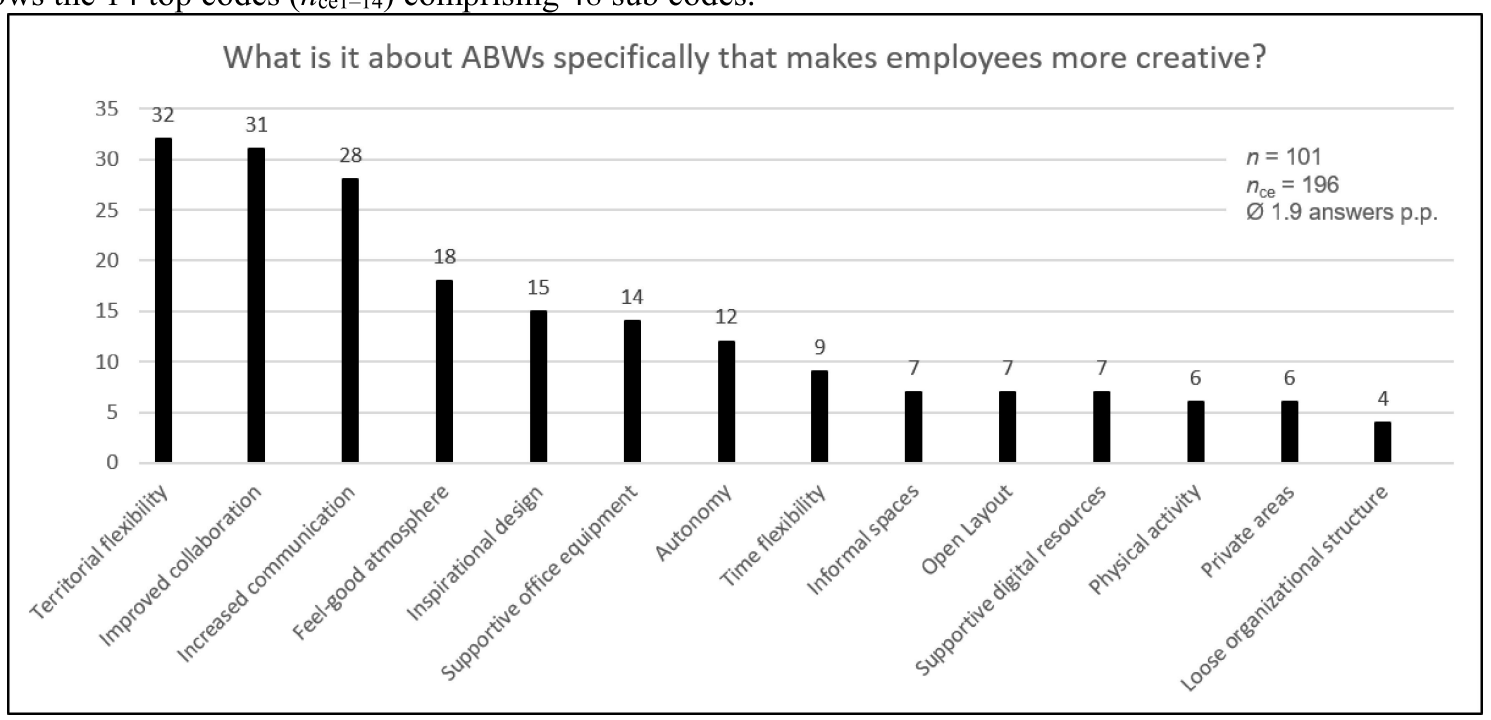

Figure 6. ABW elements that enhance creativity.

Territorial flexibility $\left(n_{\mathrm{cel}}=32 ; 16.3 \%\right)$ was considered the most important creativity-enhancing element. Associated sub codes include Availability of different workplaces and Change of activities. The following example statement clarifies the meaning of the top code:

"In particular, moving between different activities can certainly promote creativity." (Expert \#2)

The experts also attributed considerable importance to Improved collaboration $\left(n_{\mathrm{ce} 2}=31 ; 15.8 \%\right)$, which 
includes the sub codes Interdisciplinary collaboration and Learning from each other.

"I need colleagues around me so that we can help each other with creative processes and project collaboration." (Expert \#1)

Increased communication ( $n_{\mathrm{ce} 3}=28 ; 14.3 \%$ ) was the third most important element and includes the sub codes Better flow of information and Changing discussion partners.

"This kind of environment encourages communication and the emergence of new ideas." (Expert \#70)

The least mentioned creativity-enhancing elements were Physical activity $\left(n_{\mathrm{ce} 12}=6 ; 3.1 \%\right)$, Private areas $\left(n_{\mathrm{ce} 13}=\right.$ $6 ; 3.1 \%)$, and Loose organizational structure $\left(n_{\mathrm{ce} 14}=4 ; 2.0 \%\right)$.

\section{Discussion}

\subsection{Reasons for Implementing Activity-based Workspaces}

The goals of our study are to identify companies' reasons for implementing ABWs and to determine which ABW elements influence creativity. Our in-depth analysis suggests that companies implement ABWs for various reasons that reflect the needs and perspective of particular companies, as indicated in Figure 7.
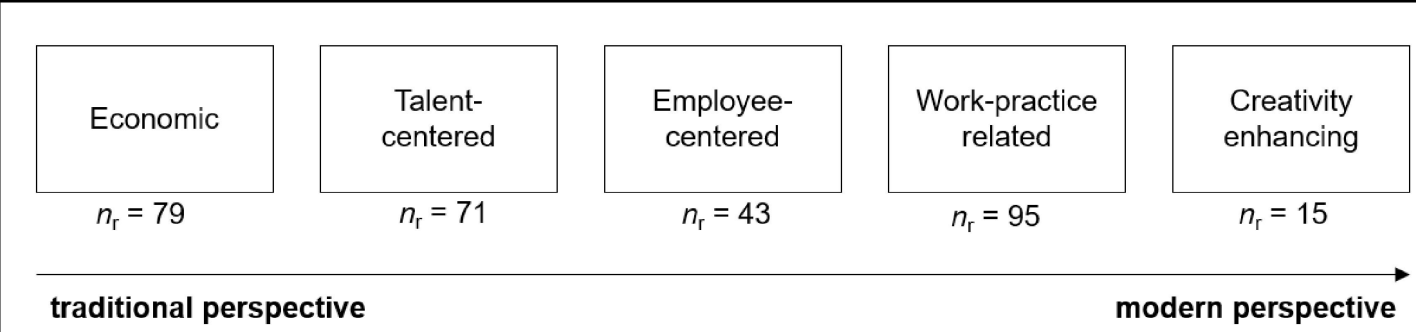

traditional perspective

modern perspective

Figure 7. Company perspectives informing $A B W$ implementation.

The results confirm that many companies still see ABW benefits primarily in economic terms. The interviewees referred to Increasing corporate success $\left(n_{\mathrm{r} 7}\right)$, Saving space $\left(n_{\mathrm{r} 8}\right)$, Saving costs $\left(n_{\mathrm{r} 9}\right)$, and Increasing productivity $\left(n_{\mathrm{r} 10}\right)$ - in short, to cost and productivity reasons that align with the traditional perspective on reasons for workplace changes (Appel - Meulenbroek et al., 2011; Kim et al., 2016; Van Ree, 2002).

Increasing employer attractiveness $\left(n_{\mathrm{r} 4}\right)$, Strengthening corporate culture $\left(n_{\mathrm{r} 5}\right)$, Modernization $\left(n_{\mathrm{r} 12}\right)$, and Offering a suitable workplace $\left(n_{\mathrm{r} 14}\right)$ were also mentioned as important reasons for implementing ABWs, indicating a talent-centered approach. As the war for talent continues to intensify (McDonnell, 2011), attracting skilled employees by offering appealing workspaces is part of keeping up with the competition (Bokor \& Fiset, 2019).

Some companies implemented ABWs as part of a more modern, employee-centered perspective, which places employees at the heart of the company and focuses on improving their well-being via PWE enhancements. Increasing employee satisfaction $\left(n_{\mathrm{r} 2}\right)$ and Increasing employee autonomy $\left(n_{\mathrm{r} 13}\right)$ are strong indicators that a company is responding to employee needs. The increase in motivation after ABWs implemention is a key driver of the employee-centered approach to workplace design (Appel-Meulenbroek et al., 2016).

Overall, the most common reasons for implementing ABWs were related to work practices. According to our findings, Improving collaboration $\left(n_{\mathrm{r} 1}\right)$, Increasing flexibility $\left(n_{\mathrm{r} 3}\right)$, and Increasing communication $\left(n_{\mathrm{r} 6}\right)$ are among the six most important company reasons for switching to an ABW. This output-oriented approach is considered to exert a positive influence on work outcomes and, therefore, on overall output, which aligns with recent evidence (Kingma, 2019; Waber et al., 2014).

Our findings confirm that companies implement $\mathrm{ABW}$ s for various reasons. Generally, the reasons reflect the traditional economic perspective $\left(n_{\mathrm{r}}=79\right)$ rather than the talent-centered $\left(n_{\mathrm{r}}=71\right)$ and employee-centered $\left(n_{\mathrm{r}}\right.$ $=43)$ perspectives. Overall, the modern work-practice perspective receives the most mentions $\left(n_{\mathrm{r}}=95\right)$ and can thus be considered the most important reason for implementing ABWs. While previous research indicates that the reasons for implementing $\mathrm{ABW}$ s change over time, traditional perspectives have not disappeared, and various reasons continue to coexist. Consequently, we formulated the following proposition:

Proposition 1a: Traditional and modern perspectives on ABW implementation coexist rather than replace each other.

Our results also suggest that more attention should be paid to creativity as a reason for implementing ABWs, as this reason was not the main driver in most cases $\left(n_{\mathrm{r}}=15\right)$. At first glance, creativity plays a minor role, accounting for only 5\% of all mentions. However, as Suckley and Nicholson (2018) noted, there is an increasing focus on office elements that influence employee creativity. Meinel et al. (2017) argued that the opportunities afforded by creative workspaces, such as ABWs, for communication and teamwork can play an important role in creativity, and this creativity-enhancing tendency may further explain the interest in ABWs. However, many of our interviewees referred to Improving collaboration and Increasing communication as reasons for implementing ABWs. The latter are prerequisites for creativity, but Increasing creativity was rarely mentioned 
directly, which indicates that companies still find this idea difficult to grasp (Kampylis \& Valtanen, 2010) and approach creativity indirectly by trying to foster communication and collaboration. Therefore, we formulated the following proposition:

Proposition 1b: Although few companies implement $A B W s$ with the direct intention of enhancing creativity, known creativity drivers, such as increasing communication and collaboration, are among the most important perceived reasons for ABW implementation.

5.2 Creativity-enhancing and Creativity-inhibiting Elements in Activity-based Workspaces

A further aim of our study was to identify which ABW elements can enhance or inhibit creativity. Using Manca et al.'s (2018) conceptual framework for collaborative workplaces to categorize the findings from the expert interviews, we assigned the top codes to the model's four deployment areas. The results are shown in Table 2. Table 2. ABW Elements That Enhance or Inhibit Creativity

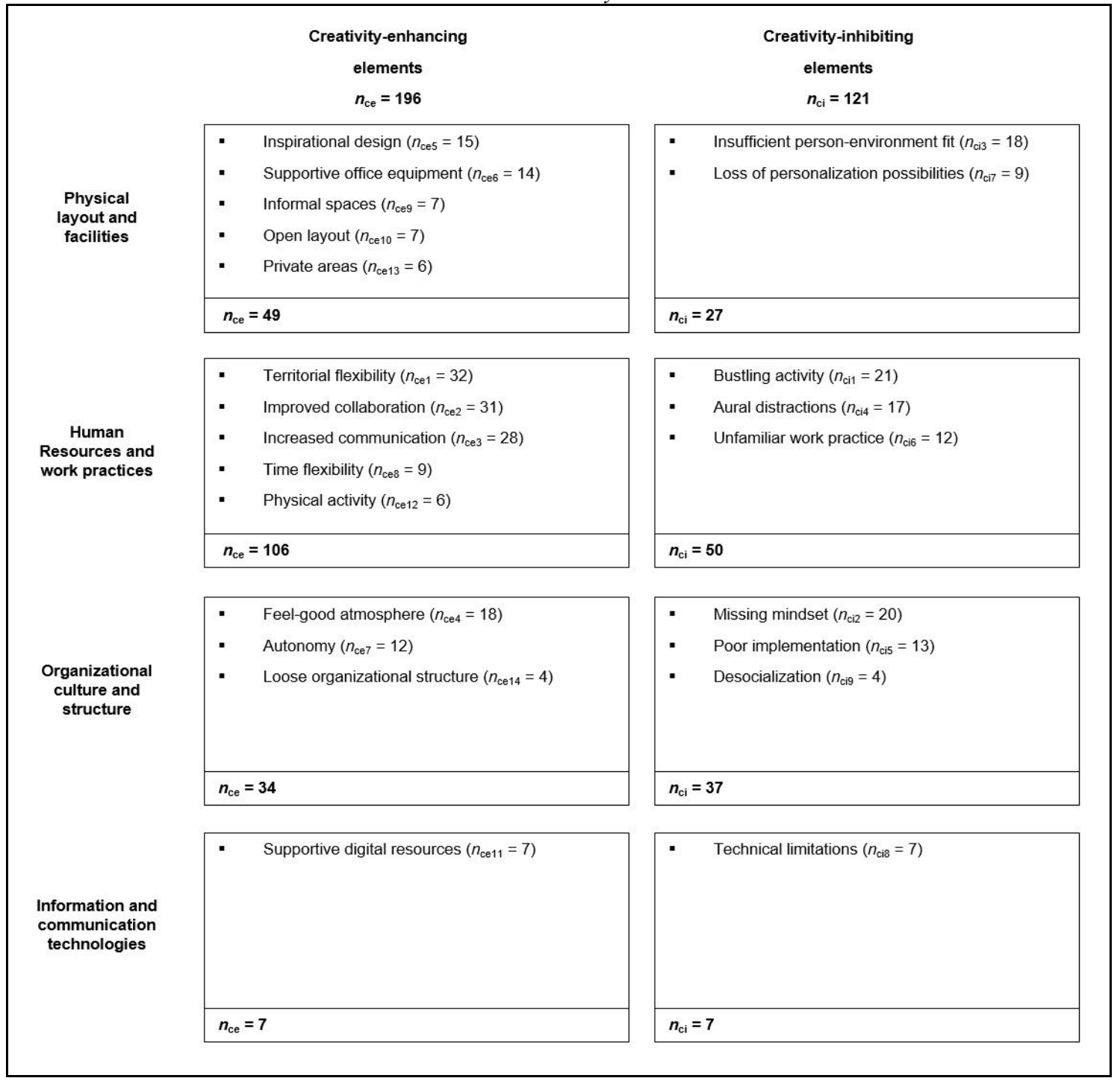

While previous studies have shown that collaborative workplaces, such as ABWs, can have both positive (see Arundell et al., 2018; Wohlers \& Hertel, 2017) and negative (see Hoff \& Öberg, 2015; Martens, 2011) effects on employee creativity, the experts interviewed in our study identified more creativity-enhancing $\left(n_{\mathrm{ce}}=196\right)$ than creativity-inhibiting $\left(n_{\mathrm{ci}}=121\right) \mathrm{ABW}$ elements. Therefore, we formulated the following proposition:

Proposition 2a: For company experts, $A B W s$ ' creativity-enhancing elements exceed the creativityinhibiting elements.

Our results also indicate that the deployment area of information and communication technologies accounts for the fewest mentions of creativity-enhancing $\left(n_{\mathrm{ce}}=7\right)$ and creativity-inhibiting $\left(n_{\mathrm{ci}}=7\right)$ elements. This suggests that the influence of technologies on creativity in ABWs is quite weak compared to other deployment areas. While our experts noted the negative effects on employee creativity due to ABWs' technical limitations (e.g., non-functioning hardware), supportive digital resources, such as mobile devices, were considered to 
enhance creativity by facilitating flexible working. Previous research has also noted the positive impact of digital communication tools on employees' creative processes in work environments (Bonnardel \& Zenasni, 2010; Kim et al., 2016). Nevertheless, the present findings indicate that the perceived impact of information and communication technologies on creativity is marginal. Therefore, we formulated the following proposition:

Proposition 2b: In ABWs, information and communication technologies play a minor role in both enhancing and inhibiting creativity.

A closer look at the role of organizational culture and structure suggests that many of the elements assigned to this deployment area can also impact employee creativity in ABWs. According to the interviewed experts, a loose organizational structure and the associated high levels of autonomy enhance creativity. ABWs' feel-good atmosphere was also mentioned as an important driver of creativity. However, corporate culture and structure were also considered to potentially have a negative impact on employee creativity in poorly implemented ABWs, characterized by the wrong mindset or desocialization, elements that have been neglected in previous research. Despite the many perceived positive effects of ABW culture and structure on employee creativity $\left(n_{\mathrm{ce}}=34\right)$, these effects were slightly outweighed by the negatives $\left(n_{\mathrm{ci}}=37\right)$, which shows that creativity-inhibiting factors must be carefully managed. Therefore, we formulated the following proposition:

Proposition 2c: Organizational culture and structure pose a particular challenge to companies implementing $A B W S$, as inadequate implementation can have predominantly negative effects on employee creativity.

When linking PWE and creativity, previous studies have focused on facilities and the provision of open, closed, and informal spaces (Martens, 2011; McCoy \& Evans, 2002; Meinel et al., 2017). However, our results clearly show that the deployment area of physical layout and facilities is ranked second among creativity-enhancing elements $\left(n_{\mathrm{ce}}=49\right)$ and third among creativity-inhibiting elements $\left(n_{\mathrm{ci}}=27\right)$. Meanwhile, human resources and work practices were seen as having the highest creativity-enhancing $\left(n_{\mathrm{ce}}=106\right)$ and creativity-inhibiting $\left(n_{\mathrm{ci}}=\right.$ 50) potential. In particular, the most relevant indicators of ABWs' creativity enhancement were said to include greater flexibility, increased or improved communication and collaboration, and increased physical activity, while aural disruptive activity, aural distractions, and unfamiliar work practices were considered to be the main inhibitors of employee creativity. Therefore, we formulated the following final proposition:

Proposition 2d: In ABWs, human resources and work practices rather than physical layout and facilities exert the greatest influence, both positive and negative, on employee creativity.

Based on these findings and Manca et al.'s (2018) conceptual framework for collaborative workplaces, we developed our own model of creativity-enhancing ABWs. Figure 8 indicates the potential of each of the four deployment areas for developing and enhancing employee creativity in ABWs. While all deployment areas clearly influence one another and contribute to ABW implementation, some areas (notably human resources and work practices) exert a greater influence on creativity and must be weighted accordingly. 


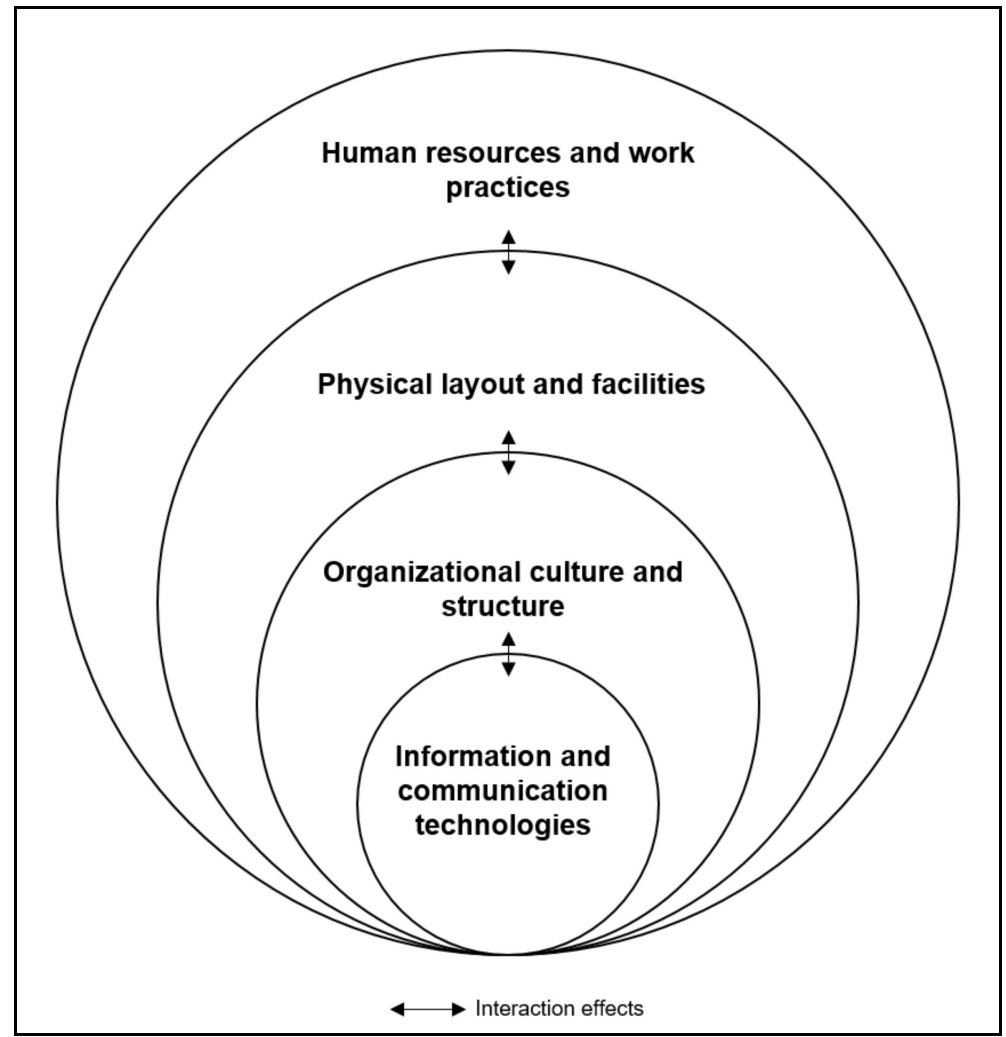

Figure 8. Framework for creativity-enhancing ABWs (Source: Authors, based on Manca et al., 2018).

\subsection{Theoretical and Practical Implications}

Our findings have important implications for scholarship. First, the study strengthens the links between ABWs and creativity by providing a much-needed overview. By identifying ABWs' specific elements that influence creativity, our findings extend the existing literature and deepen our understanding of the relationship between ABWs and creativity. Second, by specifying how different ABW elements influence creativity, our findings clarify earlier conflicting evidence on whether ABWs have an enhancing or inhibiting effect. Based on a large sample of 101 experts, our interview data show that ABWs' creativity-enhancing elements outweigh creativityinhibiting elements, implying a predominantly positive effect. Finally, building on the work of Manca et al. (2018), our model of creativity-enhancing ABWs ranks human resources and work practices as the most influential of the four deployment areas, followed by physical layout and facilities, organizational culture and structure, and information and communication technologies.

Our findings also have significant practical implications for companies implementing ABWs. First, companies should use our framework to determine which areas should be prioritized to foster employee creativity, focusing on the more influential deployment areas to inform structured implementation. Second, negative effects on employee creativity can be prevented by addressing potential creativity-inhibiting elements. For example, noise-absorbing ceiling panels and carpets can be used to reduce aural distractions, and managers should allow their employees sufficient freedom to be creative rather than imposing rules that are unduly strict. In addition, conducting employee surveys prior to ABW implementation can help ensure an adequate personenvironment fit while also encouraging a more positive mindset regarding activity-based working. Finally, as the deployment area of human resources and work practices was found to exert the strongest influence on creativity enhancement and inhibition, companies should organize workshops and training on appropriate ABW use and related work practices, with a particular emphasis on exploiting the different spaces to optimize creative output.

\section{Limitations and Future Research}

While this study provides novel in-depth insights, it has some limitations that suggest directions for future research. In their original conceptual framework for collaborative workplaces, Manca et al. (2018) also analyzed the interaction effects between deployment areas. While acknowledging the importance of these interaction effects, our study focuses on ranking the four deployment areas and has little to say about the relations between them. For example, it remains unclear how ABWs' physical layout and facilities influence human resources and work practices, and vice versa. Based on our framework for creativity-enhancing ABWs, future research should explore the direct interaction effects between these deployment areas. 
Further, this study is limited to companies located in Germany exclusively, raising the question of whether employees from other cultural regions have different requirements for a creativity-enhancing work environment. Investigations in other countries and cultures would therefore lead to an even more comprehensive understanding of ABWs' impact on creativity. This is especially important for companies that have office locations around the world, in order to assess whether their preferred PWE can be used in other countries as well or needs to be adapted.

While our findings indicate that information and communication technologies exert the least influence (both positive and negative) on employee creativity in ABWs, many employees have been unable to use company facilities during the COVID-19 pandemic, and collaboration and communication with and between their teams have depended on digital tools. It seems important to explore how this has affected creative processes in teams and how better use of these digital technologies can be made to enhance employee creativity, both now and in the future (Toumi et al., 2021). As innovation typically emerges in the PWE, future research should explore how ABWs can more fully support employee creativity in the "new normal."

\section{References}

Amabile, T. M. (1983). The social psychology of creativity: A componential conceptualization. Journal of Personality and Social Psychology, 45(2), 357. https://doi.org/10.1037/0022-3514.45.2.357

Amabile, T. M. (1988). Research in organizational behaviour. Journal of Personality and Social Psychology, 10(1), 123-167.

Amabile, T. M., \& Conti, R. (1999). Changes in the work environment for creativity during downsizing. Academy of Management Journal, 42(6), 630-640. https://doi.org/10.2307/256984

Appel-Meulenbroek, R., Oldman, T., \& van Susante, P. J. M. (2016). How employees value the support of activity-based and traditional work environments. Tampere University of Technology.

Appel - Meulenbroek, R., Groenen, P., \& Janssen, I. (2011). An end - user's perspective on activity - based office concepts. Journal of Corporate Real Estate, 13(2), 122-135. https://doi.org/10.1108/14630011111136830

Arundell, L., Sudholz, B., Teychenne, M., Salmon, J., Hayward, B., Healy, G. N., \& Timperio, A. (2018). The impact of activity-based working (ABW) on workplace activity, eating behaviours, productivity, and satisfaction. International Journal of Environmental Research and Public Health, 15(5), 1005. https://doi.org/10.3390/ijerph15051005

Bettis, R. A., Gambardella, A., Helfat, C., \& Mitchell, W. (2015). Qualitative empirical research in strategic management. Strategic Management Journal, 36(5), 637-639. https://doi.org/10.1002/smj.2317

Blok, M. M., Groenesteijn, L., Schelvis, R., \& Vink, P. (2012). New ways of working: Does flexibility in time and location of work change work behavior and affect business outcomes? Work, 41(Suppl 1), 5075-5080. https://doi.org/10.3233/WOR-2012-0800-5075

Bokor, C. V., \& Fiset, B. (2019). Activity-based workplace (ABW). PM World Journal, 8(9), 1-13.

Bonnardel, N., \& Zenasni, F. (2010). The impact of technology on creativity in design: An enhancement? Creativity and Innovation Management, 19(2), 180-191. https://doi.org/10.1111/j.1467-8691.2010.00560.x

Boutellier, R., Ullman, F., Schreiber, J., \& Naef, R. (2008). Impact of office layout on communication in a science-driven business. $R \& D$ Management, 38(4), 372-391. https://doi.org/10.1111/j.14679310.2008.00524.x

Brunia, S., Been, I. de, \& van der Voordt, T. J. (2016). Accommodating new ways of working: Lessons from best practices and worst cases. Journal of Corporate Real Estate, 18(1), $30-47$. https://doi.org/10.1108/JCRE-10-2015-0028

Budie, B., Appel-Meulenbroek, R., Kemperman, A., \& Weijs-Perree, M. (2018). Employee satisfaction with the physical work environment: The importance of a need-based approach. International Journal of Strategic Property Management, 23(1), 36-49. https://doi.org/10.3846/ijspm.2019.6372

Candido, C., Thomas, L., Haddad, S., Zhang, F., Mackey, M., \& Ye, W. (2019). Designing activity-based workspaces: Satisfaction, productivity and physical activity. Building Research \& Information, 47(3), 275289. https://doi.org/10.1080/09613218.2018.1476372

Cannell, C. F., \& Kahn, R. L. (1968). Interviewing. In G. Lindzey \& E. Aronson (Eds.), The handbook of social psychology (vol. 2, pp. 525-595). Addison-Wesley.

Coradi, A., Heinzen, M., \& Boutellier, R. (2015). A longitudinal study of workspace design for knowledge exploration and exploitation in the research and development process. Creativity and Innovation Management, 24(1), 55-71. https://doi.org/10.1111/caim.12099

De Been, I., \& Beijer, M. (2014). The influence of office type on satisfaction and perceived productivity support. Journal of Facilities Management, 12(2), 142-157. https://doi.org/10.1108/JFM-02-2013-0011

DiGiovanni, M. (2004). Developing knowledge workers on the factory floor. Development and Learning in Organizations: An International Journal, 18(4), 10-12. https://doi.org/10.1108/14777280410544556 
Edmondson, A. C., \& Mcmanus, S. E. (2007). Methodological fit in management field research. Academy of Management Review, 32(4), 1246-1264. https://doi.org/10.5465/amr.2007.26586086

Eismann, T. T., Pakos, O., Rücker, M., Meinel, M., Maier, L., \& Voigt, K. I. (2022). Understanding the mechanisms of activity-based workspaces: A case study. Environment and Behavior, 54(1), 170-210. https://doi.org/10.1177/00139165211008240

Engelen, L., Chau, J., Young, S., Mackey, M., Jeyapalan, D., \& Bauman, A. (2019). Is activity-based working impacting health, work performance and perceptions? A systematic review. Building Research \& Information, 47(4), 468-479. https://doi.org/10.1080/09613218.2018.1440958

Gioia, D. A., Corley, K. G., \& Hamilton, A. L. (2013). Seeking qualitative rigor in inductive research. Organizational Research Methods, 16(1), 15-31. https://doi.org/10.1177/1094428112452151

Goodrich, R. (1986). The perceived office: The office environment as experienced by its users. In J. D. Wineman (Ed.), Behavioral issues in office design (pp. 109-133). Van Nostrand Reinhold.

Halldorsson, F., Kristinsson, K., Gudmundsdottir, S., \& Hardardottir, L. (2021). Implementing an activity-based work environment: A longitudinal view of the effects on privacy and psychological ownership. Journal of Environmental Psychology, 78, 101707. https://doi.org/10.1016/j.jenvp.2021.101707

Haner, U.- E. (2005). Spaces for creativity and innovation in two established organizations. Creativity and Innovation Management, 14(3), 288-298. https://doi.org/10.1111/j.1476-8691.2005.00347.x

Hassanain, M. A., Alnuaimi, A. K., \& Sanni-Anibire, M. O. (2018). Post occupancy evaluation of a flexible workplace facility in Saudi Arabia. Journal of Facilities Management, 16(2), 102-118. https://doi.org/10.1108/JFM-05-2017-0021

Haynes, B. P. (2008). An evaluation of the impact of the office environment on productivity. Facilities, 26(5/6), 178-195. https://doi.org/10.1108/02632770810864970

Haynes, B. P., Suckley, L., \& Nunnington, N. (2019). Workplace alignment. Facilities (advance online publication). https://doi.org/10.1108/F-07-2018-0082

Hoff, E. V., \& Öberg, N. K. (2015). The role of the physical work environment for creative employees - A case study of digital artists. International Journal of Human Resource Management, 26(14), 1889-1906. https://doi.org/10.1080/09585192.2014.971842

Kampylis, P. G., \& Valtanen, J. (2010). Redefining creativity-Analyzing definitions, collocations, and consequences. Journal of Creative Behavior, 44(3), 191-214. https://doi.org/10.1002/j.21626057.2010.tb01333.x

Kim, J., Candido, C., Thomas, L., \& de Dear, R. (2016). Desk ownership in the workplace: The effect of nonterritorial working on employee workplace satisfaction, perceived productivity and health. Building and Environment, 103, 203-214. https://doi.org/10.1016/j.buildenv.2016.04.015

Kim, J., \& de Dear, R. (2013). Workspace satisfaction: The privacy-communication trade-off in open-plan offices. Journal of Environmental Psychology, 36, 18-26. https://doi.org/10.1016/j.jenvp.2013.06.007

Kingma, S. (2019). New ways of working (NWW): Work space and cultural change in virtualizing organizations. Culture and Organization, 25(5), 383-406. https://doi.org/10.1080/14759551.2018.1427747

Korczynski, M., May, T., \& Frenkel, S. (2002). Organizational and occupational commitment: Knowledge workers in large cooperations. Journal of Management Studies, 39(6), $775-801$. https://doi.org/10.1111/1467-6486.00311

Maher, A., \& von Hippel, C. (2005). Individual differences in employee reactions to open-plan offices. Journal of Environmental Psychology, 25(2), 219-229. https://doi.org/10.1016/j.jenvp.2005.05.002

Manca, C., Grijalvo, M., Palacios, M., \& Kaulio, M. (2018). Collaborative workplaces for innovation in service companies: Barriers and enablers for supporting new ways of working. Service Business, 12(3), 525-550. https://doi.org/10.1007/s11628-017-0359-0

Martens, Y. (2011). Creative workplace: Instrumental and symbolic support for creativity. Facilities, 29(1/2), 63-79. https://doi.org/10.1108/02632771111101331

Matsuyama, K. (2009). Structural change in an interdependent world: A global view of manufacturing decline. Journal of the European Economic Association, 7(2-3), 478-486. https://doi.org/10.1162/JEEA.2009.7.23.478

Mayring, P. (2004). Qualitative content analysis. A Companion to Qualitative Research, 1(2), 159-176.

McCoy, J. M., \& Evans, G. W. (2002). The potential role of the physical environment in fostering creativity. Creativity Research Journal, 14(3-4), 409-426. https://doi.org/10.1207/S15326934CRJ1434_11

McDonnell, A. (2011). Still fighting the "war for talent"? Bridging the science versus practice gap. Journal of Business and Psychology, 26(2), 169-173. https://doi.org/10.1007/s10869-011-9220-y

Meinel, M., Maier, L., Wagner, T., \& Voigt, K. I. (2017). Designing creativity-enhancing workspaces: A critical look at empirical evidence. Journal of Technology and Innovation Management, 1(1), 1-11.

Melián-González, S. (2019). The impact of digital technology on work. Available at SSRN. https://doi.org/10.13140/RG.2.2.22588.90246 
Nardo, M. (2003). The quantification of qualitative survey data: A critical assessment. Journal of Economic Surveys, 17(5), 645-668. https://doi.org/10.1046/j.1467-6419.2003.00208.x

Samani, S. A., Rasid, S. Z. B. A., \& Sofian, S. (2014). A workplace to support creativity. Industrial Engineering and Management Systems, 13(4), 414-420. https://doi.org/10.7232/iems.2014.13.4.414

Suckley, L., \& Nicholson, J. (2018). Enhancing creativity through workspace design. In L. Martin \& N. Wilson (Eds.), The Palgrave handbook of creativity at work (pp. 245-263). Palgrave Macmillan. https://doi.org/10.1007/978-3-319-77350-6_12

Thanem, T., Varlander, S., \& Cummings, S. (2011). Open space $=$ open minds? The ambiguities of pro-creative office design. International Journal of Work Organisation and Emotion, 4(1), 78-98. https://doi.org/10.1504/IJWOE.2011.041532

Thoring, K., Desmet, P., \& Badke-Schaub, P. (2018). Creative environments for design education and practice: A typology of creative spaces. Design Studies, 56, 54-83. https://doi.org/10.1016/j.destud.2018.02.001

Thoring, K., Gon çalves, M., Mueller, R. M., Desmet, P., \& Badke-Schaub, P. (2021). The architecture of creativity: Toward a causal theory of creative workspace design. International Journal of Design, 15(2), $17-36$.

Toumi, K., Girandola, F., \& Bonnardel, N. (2021). Technologies for supporting creativity in design: A view of physical and virtual environments with regard to cognitive and social processes. Creativity. TheoriesResearch-Applications, 8(1), 189-212. https://doi.org/10.2478/ctra-2021-0012

Van der Voordt, T. J. (2004). Productivity and employee satisfaction in flexible workplaces. Journal of Corporate Real Estate, 6(2), 133-148. https://doi.org/10.1108/14630010410812306

Van Ree, H. J. (2002). The added value of office accommodation to organizational performance. Work Study, 51(7), 357-363. https://doi.org/10.1108/00438020210449012

Veldhoen, E. (2005). The art of working. Academic Service.

Waizenegger, L., McKenna, B., Cai, W., \& Bendz, T. (2020). An affordance perspective of team collaboration and enforced working from home during COVID-19. European Journal of Information Systems, 29(4), 429-442. https://doi.org/10.1080/0960085X.2020.1800417 


\section{Appendix}

A1
Interview Guideline

Part 1: About the Interviewee

1. Could you briefly tell us something about yourself? (Age [in years)], job title and area of responsibility, job tenure [in years], industry experience [in years], management responsibility or not).

2. What do you understand by the term activity-based workspaces?

3. Do you work in an ABW? Or have you worked in one?

4. Have you played a decisive role in the design of an ABW?

\section{Part 2: About the Company}

1. How many employees work in your company?

2. In which industry is your company mainly active?

3 . How old is your company (in years)?

4. For how long has your company been working in ABWs (in years)?

\section{Part 3: Reasons for Implementing ABWs}

1. Why did your company implement an ABW?

2. What could be the goals of other companies?

3. Are there specific departments / employee groups for which the ABW is particularly suitable? Which ones?

4. Are ABWs part of your corporate strategy?

\section{Part 4: ABW Execution}

1. What does an ABW look like in your company?

2. What technical equipment do you need to work activity-based or flexibly?

3. What types of space exist in your company?

4. Which spaces are particularly suitable for which tasks?

\section{Part 5: ABW Impact}

1. What positive effects do ABWs have on the individuals in your company?

2. What negative effects do ABWs have on the individuals in your company?

3. What positive effects do ABWs have on your company in general?

4. What negative effects do ABWs have on your company in general?

\section{Part 6: ABWs and Creativity}

1. What do you need to be creative? (In other words, what stimulates the creation of new ideas?)

2. Can ABWs make employees more creative?

3. What is it about ABWs specifically that makes employees more creative?

4. What is it about ABWs specifically that can inhibit employee creativity? 


\begin{tabular}{|c|c|c|c|c|c|}
\hline \multirow[b]{2}{*}{ \# } & \multicolumn{5}{|c|}{$\begin{array}{l}\text { A2 } \\
\text { What were the reasons for implementing an } A B W \text { ? }\end{array}$} \\
\hline & Top Code & Sub Code & Mentions $n_{\mathrm{r}}$ & Example Statement & Expert \# \\
\hline \multirow[t]{5}{*}{1} & \multirow[t]{5}{*}{ Improving collaboration } & Increasing collaboration in general & 16 & $\begin{array}{l}\text { "The advantage of working in an } \mathrm{ABW} \text { is that, in the best case, you are much more collaborative }[\ldots] \text { because } \\
\text { people don't just sit in their own rooms, they get to know much more about each other." }\end{array}$ & Expert\#15 \\
\hline & & Fostering interdisciplinary exchange & 8 & $\begin{array}{l}\text { "The main goal for us was to promote more efficient official channels, for example exchange between the } \\
\text { individual departments." }\end{array}$ & Expert \#99 \\
\hline & & Creating a culture of networking & 7 & "[...] we want to encourage random conversations, random meetings, and socializing and connecting." & Expert\#75 \\
\hline & & Enabling spontaneous meetings & 4 & $\begin{array}{l}\text { "[...] that you can also talk and work in an open space across projects [...] exchanging ideas and preventing } \\
\text { classical silo thinking." }\end{array}$ & Expert\#66 \\
\hline & & Increasing teamwork in general & 4 & "[...] we need teamwork, we need areas that also support this team idea." & Expert\#83 \\
\hline \multirow[t]{4}{*}{2} & \multirow[t]{4}{*}{$\begin{array}{l}\text { Increasing employee } \\
\text { satisfaction }\end{array}$} & $\begin{array}{l}\text { Improving project-and task-oriented work } \\
\text { Increasing employee satisfaction in general }\end{array}$ & $\frac{2}{13}$ & $\begin{array}{l}\text { "We created a space where colleagues could flexibly select the space and work on their projects [...]." } \\
\text { "If employees are satisfied and happy in their jobs, they will also enhance company performance. I think that } \\
\text { always has to be the goal- - a focus on people.". }\end{array}$ & $\begin{array}{l}\text { Expert\#81 } \\
\text { Expert } \# 17\end{array}$ \\
\hline & & $\begin{array}{l}\text { Increasing employee well-being } \\
\text { Responding to employees' work needs }\end{array}$ & 9 & $\begin{array}{l}\text { "The goal is the well-being of the employee. Of course, we want to be as free as possible and have fun at work." } \\
\text { "The other reason is that [activity-based workingl is how employees will want to work in the future" }\end{array}$ & $\begin{array}{l}\text { Expert\#86 } \\
\text { Expert\#25 }\end{array}$ \\
\hline & & Increasing employer motivation & 4 & "So, I think it's important [...] to motivate employees." & Expert \#41 \\
\hline & & Improving work-life balance & 2 & "The main reason is [...] to give employees the opportunity to balance their private and professional lives." & Expert \#42 \\
\hline \multirow[t]{2}{*}{3} & \multirow[t]{2}{*}{ Increasing flexibility } & Increasing flexibility & 19 & "One goal is to increase flexibility." & Expert \#87 \\
\hline & & 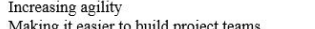 & 9 & "The original motivation $[. .$.$] was to promote reaction speed and agility."$ & $\begin{array}{l}\text { Expert \#79 } \\
\text { Expert\#14 }\end{array}$ \\
\hline \multirow[t]{5}{*}{4} & \multirow{5}{*}{$\begin{array}{l}\text { Increasing employer } \\
\text { attractiveness }\end{array}$} & $\begin{array}{l}\text { Making t teasere ro bundd project teams } \\
\text { Increasing workplace attractiveness }\end{array}$ & $\frac{1}{9}$ & 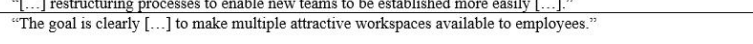 & Expert\#14 \\
\hline & & Attracting new talent & 6 & "The company wants to $[\ldots]$ attract talent." & Expert \#99 \\
\hline & & Increasing employer attractiveness in general & 6 & "What is our goal? To become a more attractive employer." & Expert\#54 \\
\hline & & $\begin{array}{l}\text { Employer branding } \\
\text { Counteracting fluctuation }\end{array}$ & 2 & "One reason is certainly employer branding $[\ldots]$ to advertise that we are not a classic large corporation." & 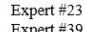 \\
\hline & & Counteracting fluctuation & & $\begin{array}{l}\text { "Ilke every consultancy, we struggle with fluctuation. } \text { l...] That's why we believe we have to do something } \\
\text { about it." }\end{array}$ & \\
\hline \multirow[t]{5}{*}{5} & \multirow{5}{*}{$\begin{array}{l}\text { Strengthening corporate } \\
\text { culture }\end{array}$} & Promoting culture change & 12 & "One reason is that the corporate culture, which is very strong in our company, is changing." & Expert\#29 \\
\hline & & $\begin{array}{l}\text { Promoting identification with the company } \\
\text { Flattening hierarchies }\end{array}$ & $\begin{array}{l}3 \\
3\end{array}$ & $\begin{array}{l}\text { "Employee identification with the company needs to be encouraged." } \\
\text { "“...] because we want a flat hierarchy, any barriers should be minimal. The managing director sits among } \\
\text { people and exchanges ideas with them." }\end{array}$ & $\begin{array}{l}\text { Expert\#24 } \\
\text { Expert \#57 }\end{array}$ \\
\hline & & Reflecting company vision & 3 & "Basically, we wanted to $[\ldots]$ reflect the company vision." & Expert \#98 \\
\hline & & Strengthening team spirit & 3 & $\begin{array}{l}\text { "At the same time, it should strengthen team spirit so that teams feel part of the whole and are understood as } \\
\text { such" }\end{array}$ & Expert\#63 \\
\hline & & Increasing transparency & 2 & "[Our] guidelines on why we are doing this and what we want to achieve with it are saying: Transparency [...]." & Expert\#73 \\
\hline
\end{tabular}

\begin{tabular}{|c|c|c|c|c|c|}
\hline \# & $\begin{array}{l}\text { A2 (continued) } \\
\text { What were the reasons } f \\
\text { Top Code }\end{array}$ & $\begin{array}{l}\text { or implementing an } A B W \text { ? } \\
\text { Sub Code }\end{array}$ & Mentions $n_{\mathrm{r}}$ & Example Statement & Expert \# \\
\hline \multirow[t]{2}{*}{6} & Increasing communication & $\begin{array}{l}\text { Increasing exchange } \\
\text { Increasing interpersonal contact }\end{array}$ & $\begin{array}{ll}17 \\
3\end{array}$ & $\begin{array}{l}\text { "[...] we want to promote exchange [...]." } \\
\text { "Another reason is that the staff feel a sense of belonging, with opportunities to play together, eat together, and } \\
\text { exchange ideas " }\end{array}$ & $\begin{array}{l}\text { Expert \#76 } \\
\text { Expert \#37 }\end{array}$ \\
\hline & & Simplifying knowledge transfer & 3 & "Mainly so that $[\ldots]$ the hurdles are low for knowledge exchange." & Expert \#57 \\
\hline 7 & $\begin{array}{l}\text { Increasing corporate } \\
\text { success }\end{array}$ & Increasing innovation & 11 & $\begin{array}{l}\text { "We try to to give as much freedom as possible }[. . .] \text { and thus the potential to unfold innovative power in the } \\
\text { mind." }\end{array}$ & Expert \#42 \\
\hline 8 & Saving space & $\begin{array}{l}\text { Increasing revenue } \\
\text { Saving space in general } \\
\text { Increasing space efficiency } \\
\text { Optimizing workplaces } \\
\text { Emphasizing desk sharing } \\
\end{array}$ & $\begin{array}{l}10 \\
7 \\
7 \\
6 \\
1 \\
\end{array}$ & $\begin{array}{l}\text { "After that, it's the usual goal [...] to bring in revenue." } \\
\text { "Ultimately, of course, it is to save space [...]" } \\
\text { "It's about using the space efficiently." [I. } \\
\text { "II's simply a matter of supporting the employees with optimized office space or collaborative spaces [...]" }\end{array}$ & $\begin{array}{l}\text { Expert } \# 33 \\
\text { Expert } \# 71 \\
\text { Expert } \# 99 \\
\text { Exxert } \# 10 \\
\text { Expert } \# 70 \\
\end{array}$ \\
\hline 9 & Saving costs & $\begin{array}{l}\text { Saving costs in general } \\
\text { Improving resource efficiency }\end{array}$ & $\begin{array}{ll}16 \\
3\end{array}$ & $\begin{array}{l}\text { "This is definitely intended to reduce and contain costs." } \\
\text { "A goal is to use all the resources that the company makes available to you and [work] in a resource-conserving } \\
\text { and resource-efficient way." }\end{array}$ & $\begin{array}{l}\text { Expert \#5 } \\
\text { Expert } \# 76\end{array}$ \\
\hline 10 & Increasing productivity & $\begin{array}{l}\text { Increasing employee productivity } \\
\text { Increasing work efficiency } \\
\text { Optimizing processes }\end{array}$ & $\begin{array}{l}9 \\
5 \\
4\end{array}$ & $\begin{array}{l}\text { "We are introducing an } \mathrm{ABW} \text { because we expect benefits in terms of emplovee productivity." } \\
\text { "[...] it's very important to us, everything that affects efficiency." } \\
\text { "For us, the objectives are [...] to optimize process flows." }\end{array}$ & $\begin{array}{l}\text { Expert \#13 } \\
\text { Expert \#97 } \\
\text { Expert \#54 }\end{array}$ \\
\hline 11 & Increasing creativity & $\begin{array}{l}\text { Increasing creativity in general } \\
\text { Encouraging creative work }\end{array}$ & $\begin{array}{c}13 \\
2\end{array}$ & $\begin{array}{l}\text { "[...] we want to build an environment that will promote }[. . .] \text { creativity }[\ldots] ., \\
\text { "We came to the conclusion that we want to do more to encourage }[\text { [... creative work." }\end{array}$ & $\begin{array}{l}\text { Expert \#4 } \\
\text { Expert \#1 }\end{array}$ \\
\hline 12 & Modernization & $\begin{array}{l}\text { Implementing modern ways of working } \\
\text { Becoming a digital company } \\
\text { Investing in the future }\end{array}$ & $\begin{array}{l}5 \\
5 \\
3 \\
3\end{array}$ & $\begin{array}{l}\text { "The managing director said he would like people to [.... ladopt a modern way of working." } \\
\text { "We wanted to move to digital working, which was no longer possible in the old set-up." } \\
\text { "[. . ] to position us for the futture." }\end{array}$ & $\begin{array}{l}\text { Expert } \# 32 \\
\text { Expert } \# 29 \\
\text { Expert } \# 36\end{array}$ \\
\hline \multirow[t]{2}{*}{13} & $\begin{array}{l}\text { Increasing employee } \\
\text { autonomy }\end{array}$ & Promoting self-responsible work & 4 & "The main reason is to promote self-responsible action $[\ldots] . "$ & Expert \#43 \\
\hline & & $\begin{array}{l}\text { Providing freedom of workspace choice } \\
\text { Increasing freedom in general }\end{array}$ & $\begin{array}{l}4 \\
1\end{array}$ & $\begin{array}{l}\text { "We want the employees to use the spaces accordingly to their current requirements." } \\
\text { "Because we believe that with these spatial structures, it is possible to provide freedom to the employees [...]." }\end{array}$ & $\begin{array}{l}\text { Expert } \# 68 \\
\text { Expert } \# 52\end{array}$ \\
\hline \multirow[t]{3}{*}{14} & $\begin{array}{l}\text { Offering a suitable } \\
\text { workplace }\end{array}$ & Offering suitable working environments & 7 & $\begin{array}{l}\text { "Why introduce activity-based working? [...] Because it offers a working environment that is ideally suited to } \\
\text { employees' activities." }\end{array}$ & Expert \#13 \\
\hline & & Enabling concentrated work & 1 & "Why do we do this? $[\ldots]$ To be able to work in a very concentrated way." & Expert \#64 \\
\hline & & Sum & 303 & & \\
\hline
\end{tabular}

A3

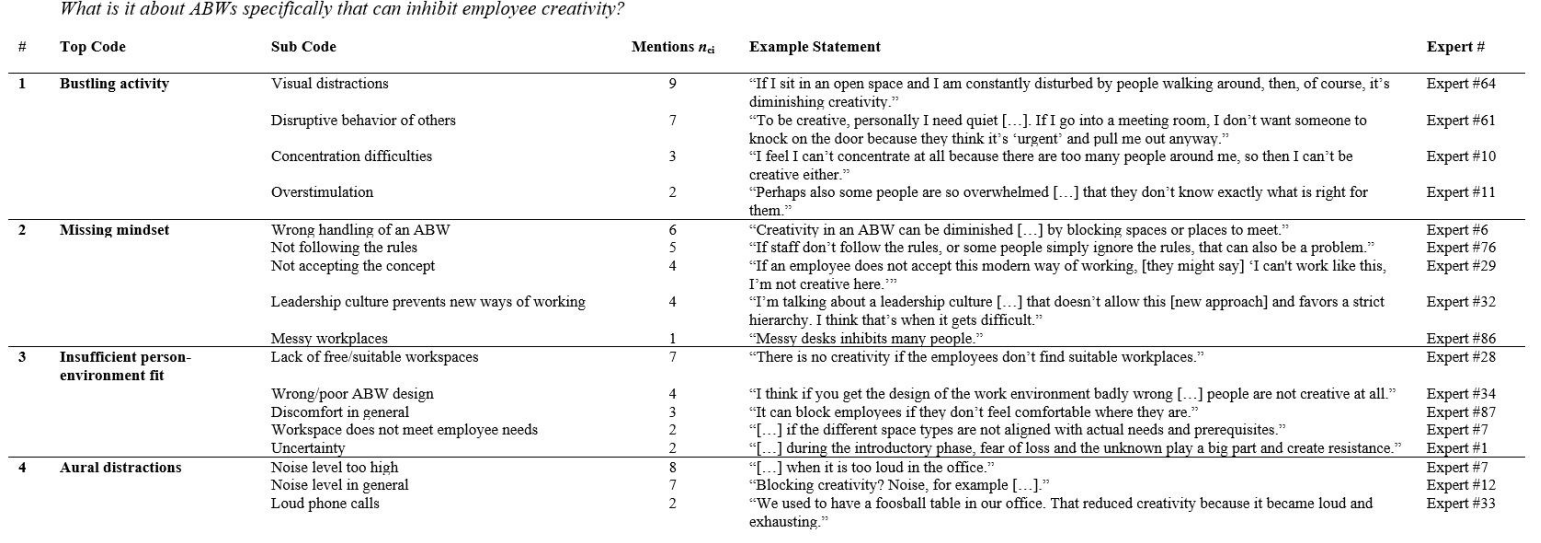




\begin{tabular}{|c|c|c|c|c|}
\hline Top Code & Sub Code & Mentions $n_{\mathrm{d}}$ & Example Statement & Expert \# \\
\hline \multirow[t]{2}{*}{ Poor implementation } & $\begin{array}{l}\text { Wrong implementation } \\
\text { Lack of change management }\end{array}$ & $\begin{array}{l}4 \\
4\end{array}$ & $\begin{array}{l}\text { "If an ABW is poorly implemented, it can kill creativity." } \\
\text { "[...] when [employees] have not been trained and don't know what they want, what they need, or what } \\
\text { is wailable" }\end{array}$ & $\begin{array}{l}\text { Expert \#35 } \\
\text { Expert \#98 }\end{array}$ \\
\hline & $\begin{array}{l}\text { Transition to } \mathrm{ABWs} \\
\text { Limiting rules }\end{array}$ & 3 & $\begin{array}{l}\text { "Difficulties are inevitable during the transition to } \mathrm{ABW} \text { s." } \\
\text { "At most it 's blocked if too manv rules are involved" }\end{array}$ & $\begin{array}{l}\text { Expert } \# 75 \\
\text { Expent \#41 }\end{array}$ \\
\hline \multirow{3}{*}{ Unfamiliar work practice } & Greater pressure & $\frac{2}{4}$ & "Creativity can be blocked because the employer demands more and creates pressure." & Expert \#97 \\
\hline & Unfamiliar concept & 4 & $\begin{array}{l}\text { "[...] if the concept is not really well implemented and the work simply does not align with the } \\
\text { emplovee's way of working, which mav have developed over a long period" }\end{array}$ & Expert \#33 \\
\hline & $\begin{array}{l}\text { Difficulties in self-organizing } \\
\text { Lack of structure }\end{array}$ & $\begin{array}{l}3 \\
1\end{array}$ & $\begin{array}{l}\text { "[...] you first have to sensitize an employee to deal with this new freedom to self-organize." } \\
\text { "A lack of structured processes [...] will always introduce an element of chaos.". }\end{array}$ & $\begin{array}{l}\text { Expert \#96 } \\
\text { Expert } \# 34\end{array}$ \\
\hline \multirow{2}{*}{$\begin{array}{l}\text { Loss of personalization } \\
\text { possibilities }\end{array}$} & Lack of individual space & 5 & "It can be [difficult] when people are sitting too close." & Expert $\# 85$ \\
\hline & $\begin{array}{l}\text { Uninspiring environment } \\
\text { No fixed workspace }\end{array}$ & $\begin{array}{l}2 \\
2\end{array}$ & $\begin{array}{l}\text { "Creativity can be inhibited if the } \mathrm{ABW} \text { is equipped with boring desk columns." } \\
\text { "Eliminating fixed workspaces can block some people's creativity." }\end{array}$ & $\begin{array}{l}\text { Expert \#3 } \\
\text { Expert \#94 }\end{array}$ \\
\hline \multirow[t]{3}{*}{ Technical limitations } & Technical hurdles & 3 & "[-...] if it's too difficult to log in at a workstation, you are blocked." & Expert \#18 \\
\hline & $\begin{array}{l}\text { Non-functioning hardware } \\
\text { Sackof hardsore }\end{array}$ & 3 & "I...] hardware that doesn't work, like my laptop or mobile phone $[\ldots . .$, & Expert $\# 16$ \\
\hline & Lack of hardware & & $\begin{array}{l}\text { "[...] when technology and hardware are limited, people are limited in what they can do, and this } \\
\text { inhbitis their creativity " }\end{array}$ & Expert $\$ 7$ \\
\hline \multirow[t]{3}{*}{ Desocialization } & Searching for someone & 2 & $\begin{array}{l}\text { "Because it can be annoying when you're looking for a certain person and you just can't find them." } \\
\text { "If [ ] you feel verv isolated the setting is not rioht" " }\end{array}$ & $\begin{array}{l}\text { Expert \#10 } \\
\text { Expert \#96 }\end{array}$ \\
\hline & $\begin{array}{l}\text { Isolation } \\
\text { Intimidation }\end{array}$ & 1 & 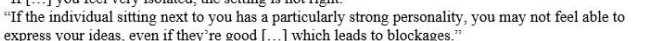 & Expert \#85 \\
\hline & sum & 12 & & \\
\hline
\end{tabular}

A4

What is it about ABWs specifically that makes employees more creative?

\begin{tabular}{|c|c|c|c|c|c|}
\hline \# & Top Code & Sub Code & Mentions $n_{\mathrm{ce}}$ & Example Statement & Expert \# \\
\hline 1 & Territorial flexibility & $\begin{array}{l}\text { Availability of different workspaces } \\
\text { Territorial flexibility in general } \\
\text { More flexible thinking } \\
\text { Change of activities }\end{array}$ & $\begin{array}{l}14 \\
12 \\
3 \\
3 \\
\end{array}$ & $\begin{array}{l}\text { "Employees need more influences through different workplaces because creativity is also based on this input." } \\
\text { "The flexibility through different spaces also increases for the employees, and that helps as well." } \\
\text { ""Definitity by motivating employeses to think more flexibly." } \\
\text { "In particular, moving between different activities can certainly promote creativity." }\end{array}$ & $\begin{array}{l}\text { Expert \#1 } \\
\text { Expert \#29 } \\
\text { Expert\#9 } \\
\text { Expert } \# 2\end{array}$ \\
\hline \multirow[t]{4}{*}{2} & Improved collaboration & More collaboration & 13 & "I need colleagues around me so that we can help each other with creative processes and project collaboration." & Expert \#1 \\
\hline & & $\begin{array}{l}\text { Interdisciplinary collaboration } \\
\text { Different points of view }\end{array}$ & $\begin{array}{l}8 \\
4\end{array}$ & $\begin{array}{l}\text { "When you have networking and interdisciplinary exchange, this makes employees more creative." } \\
\text { "That you can look at problems from multiple angles and come up with creative solutions." }\end{array}$ & $\begin{array}{l}\text { Expert } \# 22 \\
\text { Expert } \# 33\end{array}$ \\
\hline & & Learning from each other & 4 & "I believe learning from others promotes a certain level of creativity:" & Expert \#97 \\
\hline & & Establishing strong relationships & 2 & "Employees meet a larger number of people and build relationships." & Expert \#86 \\
\hline \multirow[t]{4}{*}{3} & Increased communication & $\begin{array}{l}\text { Better flow of information } \\
\text { More communication }\end{array}$ & $\begin{array}{c}12 \\
5\end{array}$ & $\begin{array}{l}\text { "By asking around, you're picking up information. That's when you' re more creative." } \\
\text { "This kind of environment encourages communication and the emergence of new ideas." }\end{array}$ & $\begin{array}{l}\text { Expert \#33 } \\
\text { Expert \#70 }\end{array}$ \\
\hline & & Unplanned communication & 4 & "To achieve higher employee creativity, we enable unplanned exchanges." & Expert \#66 \\
\hline & & Changing discussion partners & 3 & $\begin{array}{l}\text { "When }[[. .] \text { have discussions with someone different, I suddenly get a completely different perspective on } \\
\text { things." }\end{array}$ & Expert \#44 \\
\hline & & $\begin{array}{l}\text { Faster communication } \\
\text { Easier communication }\end{array}$ & $\begin{array}{r}2 \\
2 \\
\end{array}$ & $\begin{array}{l}\text { "People enter into discussions and create new ideas more quickly." } \\
\text { "[.] you can simply go somewhere else to talk with two or three people [..]" }\end{array}$ & $\begin{array}{l}\text { Expert } \# 27 \\
\text { Expert } \# 41\end{array}$ \\
\hline \multirow[t]{5}{*}{4} & Feel-good atmosphere & Diverse impressions & 7 & "You have more impressions, and this is important for creativity." & Expert \#1 \\
\hline & & Feeling good & 5 & "I am convinced that the well-being of the employees is very important $[\ldots]$ to be creative." & Expert $\# 90$ \\
\hline & & Removing blockages & 2 & "This [atmosphere] also helps you to be creative $[. .$.$] if you are blocked."$ & Expert \#2 \\
\hline & & Casual atmosphere & 2 & "And the relaxed working atmosphere can also increase creativity." & Expert \#10 \\
\hline & & Sensory stimulation & 2 & "I think it's about stimulation of the senses." & Expert \#14 \\
\hline \multirow[t]{4}{*}{5} & Inspirational design & $\begin{array}{l}\text { Interior design in general } \\
\text { Color concept }\end{array}$ & 8 & 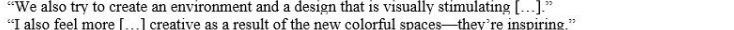 & $\begin{array}{l}\text { Expert \#83 } \\
\text { Fxpert \#98 }\end{array}$ \\
\hline & & $\begin{array}{l}\text { Color c } \\
\text { Plants }\end{array}$ & 2 & "It could also be plants on the wall that ensure your mind is activated." & $\begin{array}{l}\text { Expertt \#98 } \\
\text { Expert } \# 26\end{array}$ \\
\hline & & Aesthetic surroundings & 2 & "If there's chaos, or I'm sitting in an area that I don't find visually beautiful, I tend to feel constrained, and I & Expert $\# 23$ \\
\hline & Supportive office & Whiteboard & 7 & "Tools $[\ldots]$ like whiteboards definitely help people to be more creative." & Expert \#65 \\
\hline \multirow{3}{*}{6} & & & & & \\
\hline & & Writable walls & 2 & $\begin{array}{l}\text { "With the introduction of activity-based working, each of our meeting rooms has writable walls [...] to } \\
\text { stimulate creativity." }\end{array}$ & Expert \#74 \\
\hline & & Flipcharts & 1 & "For example, flipcharts [help me] to manage this creative process." & Expert \#95 \\
\hline
\end{tabular}

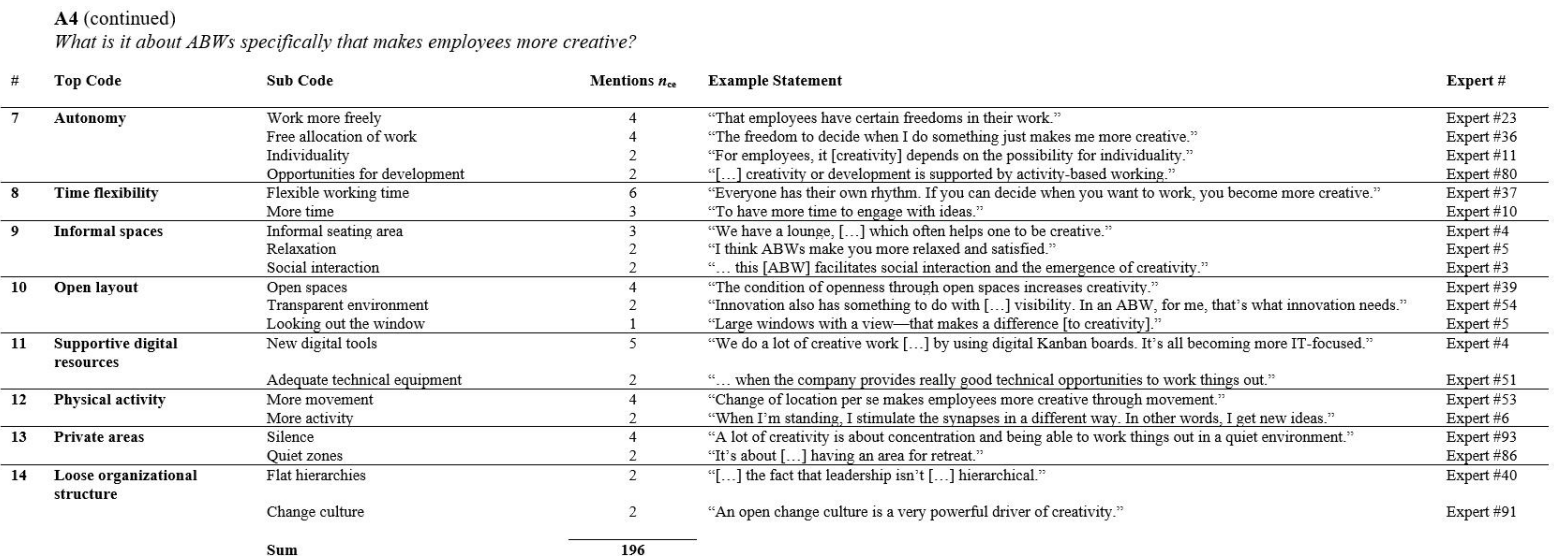

\section{Biographies of the authors}

Marc R ücker is pursuing a doctoral degree at the Department of Industrial Management at Friedrich-Alexander University Erlangen-N ürnberg. His research interests emphasize Creativity and Workplace Innovation.

Oscar Pakos is pursuing a doctoral degree at the Department of Industrial Management at Friedrich-Alexander University Erlangen-N ürnberg. His research interests emphasize Organizational Behavior and Work Environment Design.

Max Bauer is pursuing a master's degree in industrial engineering and management at Friedrich-Alexander University Erlangen-N ürnberg. His research interests emphasize Innovation Management and Creativity.

Kai-Ingo Voigt is a management professor and holds the Chair of Industrial Management at the FriedrichAlexander University Erlangen-N ürnberg. His research interest emphasize Industry 4.0, Business Model Innovation, Innovation Management, Organizational Creativity, and Work Environment Design. 